(2) Renaissance Quarterly

The Renaissance Society of America

The Graduate School and University Center

The City University of New York 


\section{RenaissanCE History}

FROM CHICAGO

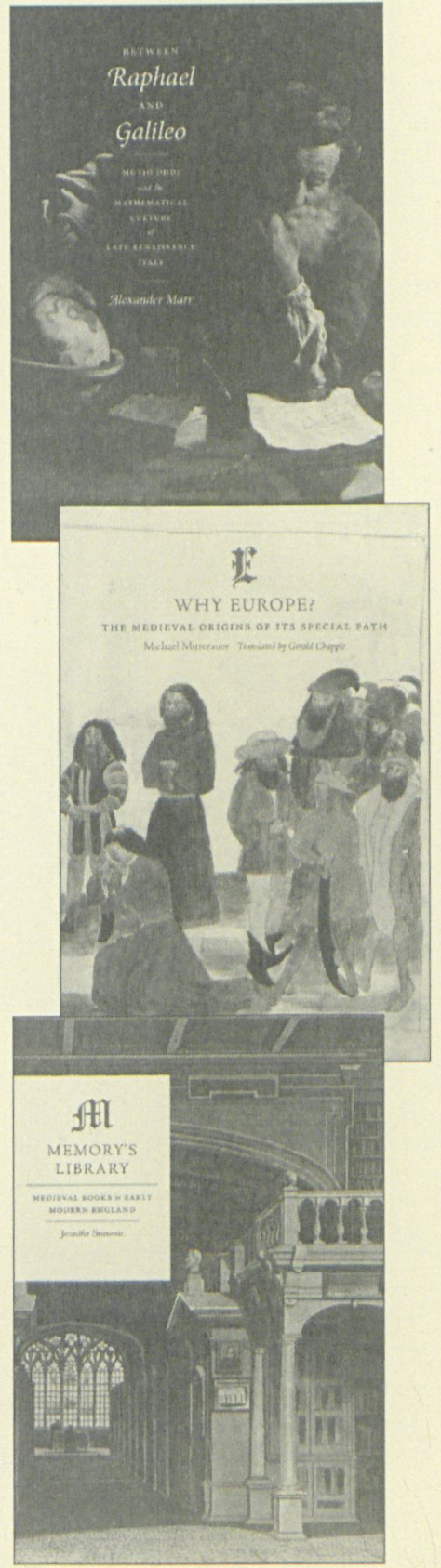

Between Raphael and Galileo

Mutio Oddi and the Mathematical Culture

of Late Renaissance Italy

\section{Alexander Marr}

"Through a fine-grained reconstruction of the daily practices of Mutio Oddi and his many friends, students, correspondents, and employers, Alexander Marr adds muchneeded texture to our map of mathematical networks in early modern Italy, the design and trade of instruments, the circulation of books and paintings about them, and the teaching of mathematics."-Mario Biagioli, University of California, Davis

CLOTH $\$ 45.00$

\section{Why Europe?}

The Medieval Origins of Its Special Path

\section{Michael Mitterauer}

Translated by Gerald Chapple

"Great books need not be fat, and Michael Mitterauer, the Viennese medievalist, has written a great book. ... Mitterauer has something to teach even veteran historians."-Frankfurter Allgemeine Zeitung "An outstanding work of nonfiction both conceptually and in its wealth of surprising details."-Rheinischer Merkur

CLOTH $\$ 49.00$

\section{Now in Paperback Memory's Library}

Medieval Books in Early Modern England

\section{Jennifer Summit}

"A stimulating and rewarding book, well calculated to make us rethink many aspects of the history of late medieval and early modern libraries."-Elisabeth LeedhamGreen, American Historical Review PAPER $\$ 27.50$

The University of Chicago Press - www.press.uchicago.edu 